\title{
Retention of iris supported intraocular lenses at the time of penetrating keratoplasty for pseudophakic corneal oedema
}

\author{
M J ROPER-HALL AND M T WATTS \\ From the Birmingham and Midland Eye Hospital, Church Street, Birmingham B3 2NS
}

SUMMARY The long-term follow-up of patients undergoing penetrating keratoplasty for pseudophakic corneal oedema is reported. The cause and frequency of corneal decompensation following intracapsular cataract extraction with insertion of an iris supported lens was assessed and found to be unrelated to the implant in the majority of cases. The most common cause of decompensation was endothelial touch during the cataract extraction. In all eyes the intraocular lens was retained at the time of penetrating keratoplasty. The hazards of removal of the lens are discussed and the recommendations made that lenses be retained when penetrating keratoplasty is undertaken for pseudophakic corneal oedema, other than in exceptional cases.

Pseudophakic corneal oedema is one of the leading indications for penetrating keratoplasty. ${ }^{2}$ Its incidence may be higher in intracapsular cataract extraction with insertion of an iris clip lens than in extracapsular surgery with a posterior chamber lens..$^{3}$

This has led to the false assumption that the continued presence of an iris supported lens in the eye after penetrating keratoplasty will necessarily prejudice the survival of a corneal graft. Some authors have recommended that all iris supported lenses be removed at the time of penetrating keratoplasty for pseudophakic corneal oedema, ${ }^{1}$ though this remains a controversial issue. ${ }^{4}$

We present the results of follow-up of all the patients under the care of the senior author and who required penetrating keratoplasty for pseudophakic corneal oedema in the presence of an iris supported lens over the period 1971-84. Particular attention is drawn to the original cause of endothelial decompensation necessitating the graft and of the subsequent survival of the graft in patients retaining the iris supported lens.

The results lead to the conclusion that removal of the intraocular lens is contraindicated except when conditions exist causing a shallow anterior chamber, with the resulting risk of endothelial touch.

\section{Materials and methods}

The records of 675 cases of intracapsular cataract Correspondence to M J Roper-Hall. extraction with the placement of a Binkhorst fourloop lens performed during the period 1971-84 were studied. The incidence of postoperative endothelial decompensation was noted as well as that of peroperative endothelial touch. The patients who subsequently underwent penetrating keratoplasty for corneal oedema from whatever cause were reviewed and the cause of their endothelial decompensation recorded.

All cataract surgery was performed by a standard technique, described by the senior author, ${ }^{5}$ with the use of chymotrypsin prior to cryoextraction of the lens. The intraocular lens was placed obliquely and, for maximum stability, prevented from rotating by a single iris suture round the upper, anterior loop of the lens. Two peripheral iridotomies were made.

The subsequent corneal grafting was undertaken by a number of surgeons, using either 16 interrupted 10/0 sutures or a combination of eight interrupted and one continuous. In all patients the intraocular lens was retained at the time of keratoplasty. In one patient an adhesion between the lens loop suture and the cornea was divided, and in another the anterior loops of the lens were removed owing to the shallowness of the anterior chamber and the suspicion of touch of the corneal endothelium. A further two patients had an extra 10/0 Prolene suture inserted to fix the inferior lens loop to the iris, for increased stability. One patient required a limited anterior vitrectomy owing to herniation of vitreous through the peripheral iridotomies at the time of 


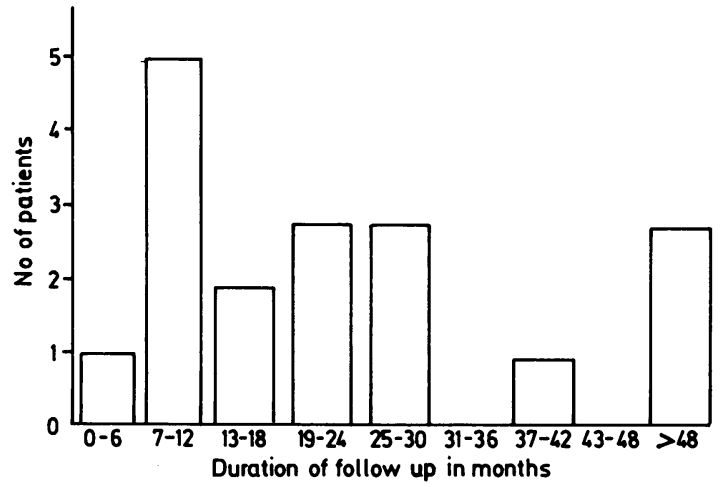

Fig. 1 Distribution of duration of follow-up after keratoplasty.

keratoplasty. No vitreous was present in the anterior chamber in the other cases.

The patients and their notes were reviewed between 6 and 70 months after keratoplasty (mean 24.5 months). Details of follow-up period are shown in Fig. 1. In all cases the endothelial status as assessed prior to cataract extraction was noted, the time following surgery at which endothelial decompensation was first noted, and the suspected factors contributing to it. The per- and postoperative complications of cataract surgery were studied and the current state of the corneal graft and visual acuity. The presence or absence of clinical cystoid macular oedema was recorded, as defined by the presence of visible macular oedema in association with reduction of visual acuity to $6 / 12$ or below.

\section{Results}

Of 675 cataract extractions, endothelial decompensation causing a reduction of visual acuity to less than $6 / 12$, and hence requiring penetrating keratoplasty, developed in 18. The reasons for the corneal decompensation following cataract surgery are listed in Table 1. The commonest cause was peroperative endothelial touch, the occurrence of which was

Table 1 Causes of corneal decompensation, and time in months following cataract extraction of its occurrence

\begin{tabular}{llc}
\hline Cause of decompensation & $\begin{array}{l}\text { No. of } \\
\text { patients }\end{array}$ & $\begin{array}{l}\text { Time postop. } \\
\text { (mean in } \\
\text { months) }\end{array}$ \\
\hline $\begin{array}{l}\text { Lens suture touching endothelium } \\
\text { Pupil block or shallow anterior chamber }\end{array}$ & 1 & 64 \\
$\quad 3$ & 14 \\
causing lens-corneal touch & & \\
Peroperative endothelial touch & 6 & 35 \\
Paised intraocular pressure & 4 & 44 \\
Loop distocation & 3 & 24 \\
& 1 & 130 \\
\hline
\end{tabular}

Table 2 Reasons for failure of four corneal grafts

\begin{tabular}{ll}
\hline Patient & Reason for failure \\
\hline 1 & $\begin{array}{c}\text { Endothelial failure secondary to raised intraocular pressure; } \\
\text { herpes simplex infection }\end{array}$ \\
2 & $\begin{array}{l}\text { Immunological graft rejection } \\
3\end{array}$ \\
$\begin{array}{c}\text { Peripheral anterior synechiae pulling lens loop to corneal } \\
\text { endothelium }\end{array}$ \\
Lens touch due to postkeratoplasty wound leak and \\
shallowing of the anterior chamber
\end{tabular}

always specifically recorded in the operation notes. Although endothelial touch was recorded in 35 of the 675 operations, it led to endothelial decompensation affecting vision in only six of the eyes, and the other 29 cases in which touch was recorded have not subsequently decompensated.

It is interesting to note that all six eyes had been operated on prior to the widespread use of sodium hyaluronate. It is also of importance that peroperative endothelial trauma is not usually immediately manifest: indeed the mean time between surgery and the first signs of decompensation was 35 months. Study of all intracapsular cataract extractions with insertion of Binkhorst lenses and followed up for more than five years showed some endothelial corneal decompensation in $2 \cdot 1 \%$ of eyes at two years and $6.6 \%$ at five years. It was often peripheral only, and did not affect visual acuity. Clinically significant corneal decompensation, defined as that causing a reduction in visual acuity to less than $6 / 12$, occurred in only 18 patients and was treated with penetrating keratoplasty.

The corneal graft remained clear and without further problems in 14 of the 18 patients. The reasons for graft failure in the other four are shown in Table 2. The two patients whose grafts opacified owing to raised intraocular pressure together with, respectively, herpes simplex infection and graft rejection, had successful repeat keratoplasty. The former achieved $6 / 60+1$ acuity only, as a result of extensive

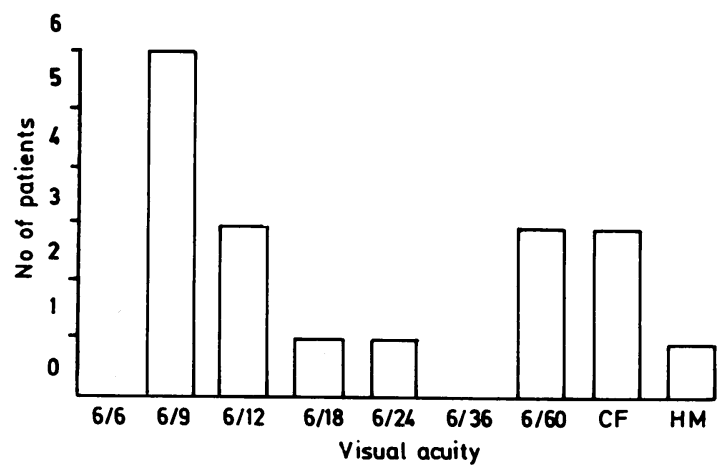

Fig. 2 Current corrected visual acuity. 
glaucomatous nerve damage, and the latter $6 / 24$, acuity being limited by the presence of cystoid macular oedema.

One of the other two patients declined repeat keratoplasty, and the other is awaiting surgery.

The current visual acuity of all 18 patients is shown in Fig. 2, and the reasons for poor vision in those achieving less than $6 / 12$ are summarised in Table 3.

\section{Discussion}

The results of the study highlight a number of features of relevance to the management of pseudophakic corneal oedema. The first is that corneal oedema severe enough to require penetrating keratoplasty is a relatively uncommon complication of intracapsular cataract extraction with insertion of an iris supported lens $(2 \cdot 7 \%)$, and that in most cases factors other than the intraocular lens appeared to be responsible for the endothelial decompensation. These included peroperative touch, pre-existing corneal disease, and raised intraocular pressure prior to cataract extraction. The incidence here of pseudophakic corneal oedema compares favourably with that of the combined experience of a number of authors of $3.6 \% .^{6}$ Although the incidence of endothelial touch was 35 out of $675(5.2 \%)$, in only six cases $(0.9 \%)$ did this subsequently cause clinically significant corneal oedema. In those cases in which the intraocular lens did appear to have contributed, the problem was remediable without recourse to removal of the lens. For example, in one patient the suture retaining the lens was intermittently touching the corneal endothelium, and it was possible to trim this at the time of keratoplasty; in two other patients an unstable lens was stabilised by an additional suture through the lower, anterior lens loop.

Indeed, the hazards of attempted removal of a lens are considerable. Hall and Muenzler, ${ }^{7}$ in removing 53 intraocular lenses from patients with pseudophakic corneal oedema, needed to perform anterior vitrectomy in all but two. Waring et al., in removing all intraocular lenses at keratoplasty, achieved a final visual acuity of $6 / 12$ or better in only $16 \%{ }^{8}$ Arentsen and Laibson also found a better prognosis if the intraocular lens was retained. ${ }^{9}$ Busin et al..$^{10}$ pointed out the increased incidence of cystoid macular

Table 3 Reasons for visual acuity of less than 6/12 after keratoplasty

\begin{tabular}{ll}
\hline Pathology & No. of patients \\
\hline Cystoid macular oedema & 2 \\
Glaucomatous nerve damage & 2 \\
Age related macular degeneration & 2 \\
Diabetic maculopathy & 1 \\
Opaque corneal graft & 2 \\
\hline
\end{tabular}

oedema when vitreous is removed, a fact which had been previously suggested by a number of authors. ${ }^{11-14}$ The risk of retinal detachment is also increased. Waring stressed the importance of careful peroperative examination of an intraocular lens prior to deciding whether to remove it, including retraction of the iris to inspect the posterior loops and inspection of the angle either with a dental mirror or by inversion of the limbus. ${ }^{\text {is }}$

The term pseudophakic corneal oedema is defined as irreversible corneal oedema in an aphakic eye with an intraocular lens'. It does not imply that the lens is responsible for the oedema but simply that it is witness to it. Though it would be fallacious to suggest that the iris supported lens is never responsible for pseudophakic corneal oedema, it is equally imprudent to remove such a lens indiscriminately, without thought as to both the necessity of doing so and the potential hazards involved.

\section{References}

1 Sugar A, Meyer RF, Heidemann D, et al. Specular microscopic follow-up of corneal grafts for pseudophakic bullous keratopathy. Ophthalmology 1985; 92: 325-30.

2 Robin JB, Gindi JJ, Koh K, et al. An update of the indications for penetrating keratoplasty. Arch Ophthalmol 1986; 104: 87-9.

3 Taylor DM, Atlas BF, Romanchuk KG, Stern AL. Pseudophakic bullous keratopathy. Ophthalmology 1983; 90: 19-24.

4 Waring GO III. Penetrating keratoplasty for pseudophakic corneal edema with exchange of intraocular lenses. Arch Ophthalmol 1987; 105: 58-62.

5 Roper-Hall MJ. Sophistication in intraocular lens surgery. Trans Ophthalmol Soc UK 1985; 104: 500-6.

6 Drews RC. Symposium: complications of modern surgical procedures, inflammatory response, endophthalmitis, corneal dystrophy, glaucoma, retinal detachment, dislocation, refractive error, lens removal, and enucleation. Ophthalmology 1978; 85: 164-75.

7 Hall JR, Muenzler WS. Intraocular lens replacement in pseudophakic bullous keratopathy. Trans Ophthalmol Soc UK 1985; 104: 541-5.

8 Waring GO III, Welch NS, Wilson LA, Cavanagh HD. Results of penetrating keratoplasty in 123 eyes with pseudophakic or aphakic corneal edema. Ophthalmology 1983; 90: 25-32.

9 Arentsen JJ, Laibson PR. Surgical management of pseudophakic bullous corneal edema: complications and visual results following penetrating keratoplasty. Ophthalmic Surg 1982; 13: 371-3.

10 Busin M, Arffa RC, McDonald MB, Kaufmann HE. Intraocular lens removal during penetrating keratoplasty for pseudophakic bullous keratopathy. Ophthalmology 1987; 94: 505-9.

11 Jaffe NS, Clayman HM, Jaffe MS. Cystoid macular edema after intracapsular and extracapsular cataract extraction with and without an intraocular lens. Ophthalmology 1982; 89: 25-9.

12 Meyer RF, Sugar A. Penetrating keratoplasty in pseudophakic bullous keratopathy. Am J Ophthalmol 1980; 90: 677-81.

13 Waltman SR. Penetrating keratoplasty for pseudophakic bullous keratopathy. Arch Ophthalmol 1981; 99: 415-6.

14 Arentsen JJ, Laibson PR. Surgical management of pseudophakic corneal edema: complications and visual results following penetrating keratoplasty. Ophthalmic Surg 1982; 13: 371-3.

15 Waring GO III. Management of pseudophakic corneal edema with reconstruction of the anterior ocular segment. Arch Ophthalmol 1987; 105: 709-15. 